\title{
Supernumerary chromosome segments and intrabivalent chiasma redistribution in Pyrgomorpha conica (Orthoptera)
}

\author{
JOSE A. SUJA*, CARMEN ANTONIO, CARLOS GARCIA DE LA VEGA† \& \\ JULIO S. RUFAS \\ Unidad de Biologia Celular and † Unidad de Genética, Departamento de Biologia, Edificio de Biologia, Facultad de \\ Ciencias, Universidad Autónoma de Madrid, 28049-Madrid, Spain
}

\begin{abstract}
Two kinds of supernumerary chromosome segments have been found on the megameric chromosome of the grasshopper Pyrgomorpha conica. One of them is euchromatic and distally located while the other one is heterochromatic and proximally located. Their effects on chiasma distribution in heterozygous, homozygous and doubly heterozygous bivalents for these segments have been analyzed. Both segments distort chiasma distribution so that the single chiasma is preferentially formed far from the location of each supernumerary segment. This effect is more pronounced in bivalents that are homozygous for the presence of the proximal heterochromatic segment. In doubly heterozygous bivalents that possess both segments on the same chromosome the chiasma distribution is significantly different from that observed in heterozygous bivalents for each segment and a significant frequency of univalents was scored.
\end{abstract}

Keywords: chiasma distribution, chromosome pairing, meiosis, supernumerary chromosome segments.

\section{Introduction}

Supernumerary heterochromatin is one source of variation in DNA content of eukaryotic genomes. This kind of heterochromatin is usually found in the form of supernumerary segments that are commonly polymorphic and have no effect on the viability of affected individuals (John, 1973). Supernumerary heterochromatic segments have been found both in plants (Ruiz Rejón \& Ruiz Rejón, 1985) and animals. However, they have been most extensively studied in orthopteroid insects (Hewitt, 1979; John \& King, 1985) in which different chromosome banding techniques have demonstrated the heterogeneity of supernumerary segments in DNA composition (Camacho et al., 1984; John et al., 1985; Gosálvez et al., 1987; Sentís et al., 1989; Rodriguez Iñigo et al., 1993). Although these segments do not modify exophenotypic characters of affected individuals, certain effects on the nucleolar organizer activity of the autosomes (Cabrero et al., 1986), mean cell chiasma frequency (Hewitt, 1979) and chiasma distribution in the carrier bivalents (John, 1981; John \& King, 1985) have been described.

\footnotetext{
${ }^{*}$ Correspondence.
}

Miklos \& Nankivell (1976) first described a change in the standard pattern of chiasma distribution in grasshopper bivalents heterozygous for the presence of distal heterochromatic segments. Since then it has invariably been observed that the presence of supernumerary segments produces chiasma redistribution in the carrier bivalents, i.e. chiasmata are preferentially formed far from where segments are located. This effect is independent of the euchromatic or heterochromatic nature of the segment (Camacho et al., 1984; Cabrero et al., 1986), its position and its response to C-banding (García-Lafuente et al., 1983; Navas-Castillo et al., 1985). García-Lafuente et al. (1983) suggested that the presence rather than the characteristics of the supernumerary segment would control the chiasma position. Moens et al. (1989) proposed that in the grasshopper Chloealtis conspersa, at least in the case of proximal and distal segments, "the redistribution of chiasmata is a consequence of synaptic interference produced by the misalignment of homologous chromosomes where they are attached to the nuclear envelope'. Santos et al. (1993), in turn, have shown that in the grasshoppers Chorthippus jacobsi and Euchorthippus pulvinatus the bivalents heterozygous for the presence of supernumerary segments show 
complete pairing during pachytene. These authors have suggested that heterosynapsis implying nonhomologous pairing may explain the absence of chiasmata in the vicinity of the segments and consequently the chiasma redistribution observed in carrier bivalents.

In the present study we have analysed the effect of both a distal euchromatic and a proximal heterochromatic supernumerary segment on chiasma distribution in the megameric bivalent of the grasshopper Pyrgomorpha conica, both in heterozygotes and homozygotes. Our results show that the standard chiasma distribution is disturbed when the bivalent structure is modified by the addition of either kind of segment. Interestingly, in doubly heterozygous megameric bivalents, where both types of segment appear on the same chromosome, the novel chiasma distribution reflects the interference effect of both segments. Moreover, a significant frequency of univalents was scored in doubly heterozygous karyomorphs. We discuss the meaning of such chiasma redistributions, taking into account modifications of the pairing process and possible interference effects caused by the segments.

\section{Materials and methods}

Adult males of Pyrgomorpha conica from the same natural population were collected at Aranjuez (Madrid, Spain) during three consecutive years (Table 1). Testes were removed and fixed in 3:1 ethanol:glacial acetic acid and stored in the fixative at $-20^{\circ} \mathrm{C}$. Lacto-propionic orcein staining and $\mathrm{C}$-banding were used on squashes of single seminiferous tubules.

The male chromosome complement of $P$. conica is composed of nine pairs of autosomes plus a single sex (X) chromosome. All chromosomes possess terminal centromeres (Fig. 2a).

\section{Results}

\section{Supernumerary segments in the megameric chromosome}

In this species the megameric bivalent is the smallest in size and shows positive heteropycnosis throughout prophase I. In orcein-stained slides the standard megameric chromosome $(\mathrm{S})$ shows two proximal heterochromatic blocks of different size (1 and 2) separated by a small euchromatic portion and a distal euchromatic region below block 2 (Figs $1 \mathrm{a}, 2 \mathrm{c}$ and $3 \mathrm{~b}$ ). After $\mathrm{C}$-banding the centromere is detected as a dot located in the apex of the larger heterochromatic block (1) (Fig. 2b). Moreover, we have found megameric chromosomes which may possess two kinds of extra segments:
Table 1 Number of individuals presenting different megameric chromosome karyomorphs during 3 consecutive years

\begin{tabular}{lrcc}
\hline Karyomorph & 1986 & 1987 & 1988 \\
\hline S/S & 84 & 103 & 39 \\
S/H & 3 & 8 & 2 \\
H/H & 1 & - & - \\
S/E & 10 & 9 & 4 \\
S/EH & 2 & - & - \\
Total & 100 & 120 & 45 \\
\hline
\end{tabular}

S/S: standard bivalent; $\mathrm{S} / \mathrm{H}$ : bivalent heterozygous for the proximal heterochromatic segment; $\mathrm{H} / \mathrm{H}$ : bivalent homozygous for the proximal heterochromatic segment; S/E: bivalent heterozygous for the distal euchromatic segment; S/EH: bivalent doubly heterozygous for both the distal euchromatic and the proximal heterochromatic segments located on the same chromosome.

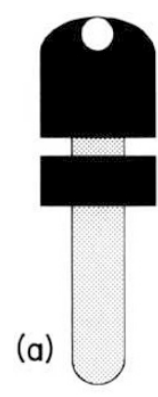

(b)

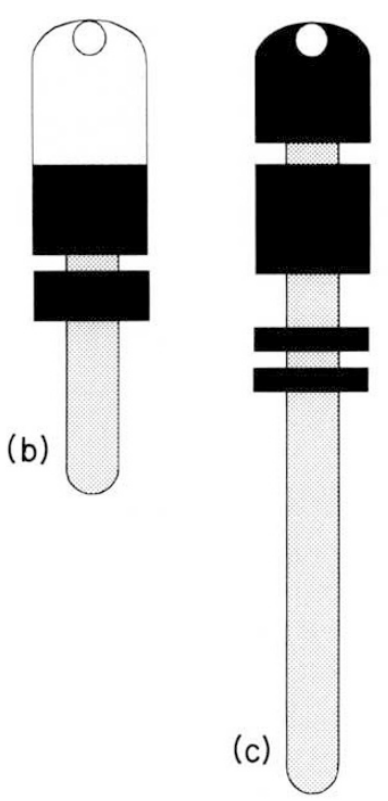

(d)

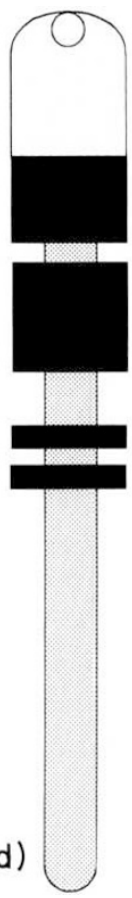

Fig. 1 Schematic representation of the four kinds of megameric chromosomes. (a) Standard megameric. (b) Megameric chromosome with the proximal heterochromatic segment. (c) Megameric chromosome with the distal euchromatic segment. (d) Megameric chromosome with both segments (for explanations see text).

a euchromatic supernumerary segment $(E)$ located in a distal position and a proximal heterochromatic segment $(\mathrm{H})$.

The distal euchromatic segment $(\mathrm{E})$ has always been found in the heterozygous condition (Table 1). In these 
Fig. 2 Standard megameric bivalents (S/S). (a), (c)-(e) Orcein staining. (b) C-banding.

(a) Diakinesis. The sex chromosome (X) and the megameric bivalent (arrow) are indicated. Bar represents $10 \mu \mathrm{m}$. (b) Selected S/S diplotene bivalent. The heterochromatic blocks are not C-banded; instead only one spot in the centromeric region of each chromosome is present (arrows). Bar represents $5 \mu \mathrm{m}$. (c)-(e) Selected S/S bivalents with proximal (c), interstitial (d) and distal (e) chiasmata. Bar represents $5 \mu \mathrm{m}$.

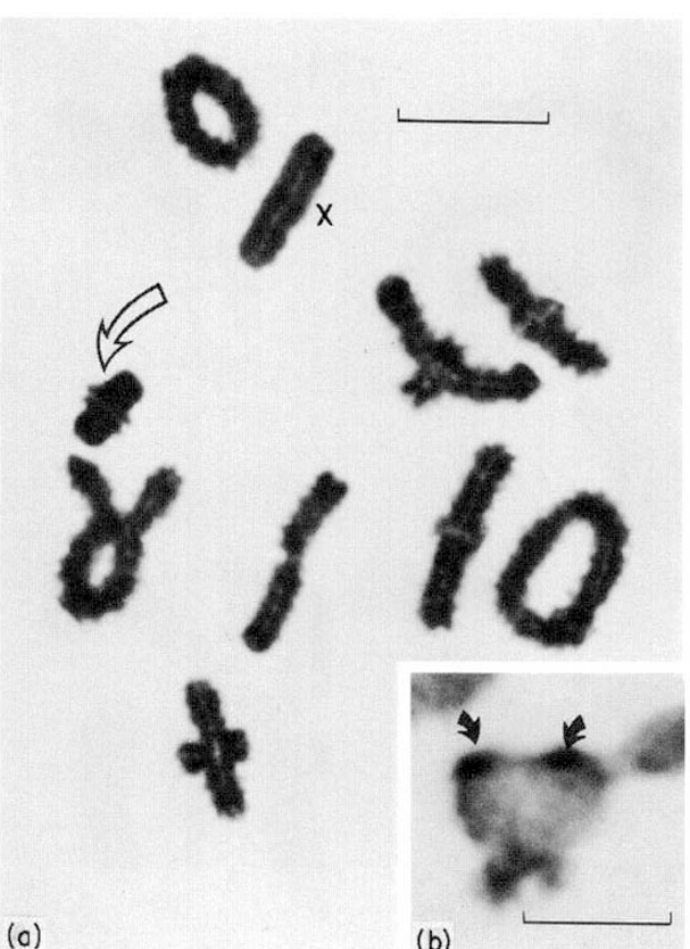

(a)

(b)

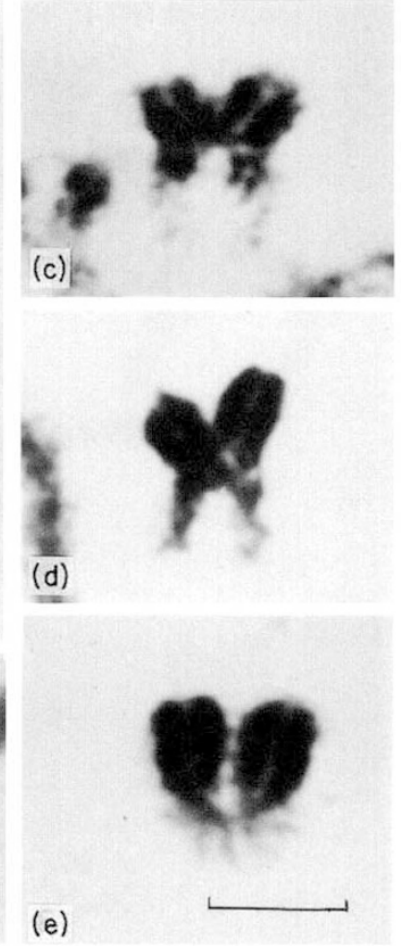

cases, large differences in size between both homologues are clearly observable throughout the first meiotic division (Fig. 3). During early diplotene the chromosome bearing the segment $(E)$ shows a large block 2 and two thin interstitial heterochromatic regions interspersed within the distal euchromatic segment (Figs $1 \mathrm{c}$ and $3 \mathrm{~b}$ ).

Bivalents both heterozygous $(\mathrm{S} / \mathrm{H})$ and homozygous $(\mathrm{H} / \mathrm{H})$ for the presence of the proximal heterochromatic supernumerary segment $(\mathrm{H})$ have been found (Table 1, Fig. 5). The segment is between the centromere and the heterochromatic block 1 which in this case is shorter than that present in standard chromosomes (Figs $1 \mathrm{~b}$ and 5e). This segment is negatively heteropycnotic during the first meiotic division, and stains positively after C-banding (data not shown).

The presence of these supernumerary segments gives rise to four kinds of megameric chromosomes $(\mathrm{S}, \mathrm{E}, \mathrm{H}$ and EH) (Fig. 1) and ten possible distinct karyomorphs. We have sampled the same population during 3 consecutive years and have only found five of these karyomorphs (Table 1). During the three years of sampling the frequencies of each mutation ( $E$ and $H$ ) are similar (Table 2).

\section{Chiasma distribution}

Chiasma distribution was scored in each kind of megameric bivalent to learn whether the presence of the segments modifies this feature. The complex structure of these chromosomes allows distinct chromosome regions where chiasmata may form to be differentiated. Thus, we have considered to be proximal chiasmata those located in the euchromatin between the two proximal heterochromatic blocks (1 and 2); interstitial chiasmata, which are those formed within the distal euchromatic region and distal chiasmata, those formed at the very end of chromosomes with or without the euchromatic supernumerary segment $(\mathrm{E})$.

In standard megameric bivalents $(\mathrm{S} / \mathrm{S})$ a single chiasma is always formed. Examples of the three possible locations have been scored (Fig. 2c-e). However, locations are not randomly distributed and more than half the bivalents analysed ( 66.4 per cent) show distal chiasmata (Table 3, Fig. 7). Moreover, no megameric univalents were observed.

During diplotene, heterozygous bivalents (S/E) possessing the euchromatic supernumerary segment commonly show a single proximally (Fig. 3b, c) or distally (Fig. 3e) located chiasma. Chiasmata are preferentially formed in proximal positions (Table 4). No interstitial chiasma was scored. However, some 14 per cent of the bivalents show two associations (Fig. $3 \mathrm{~d}$, Table 4). To learn whether they represent true chiasmata the number and location of associations in bivalents at diplotene, diakinesis and metaphase I were 


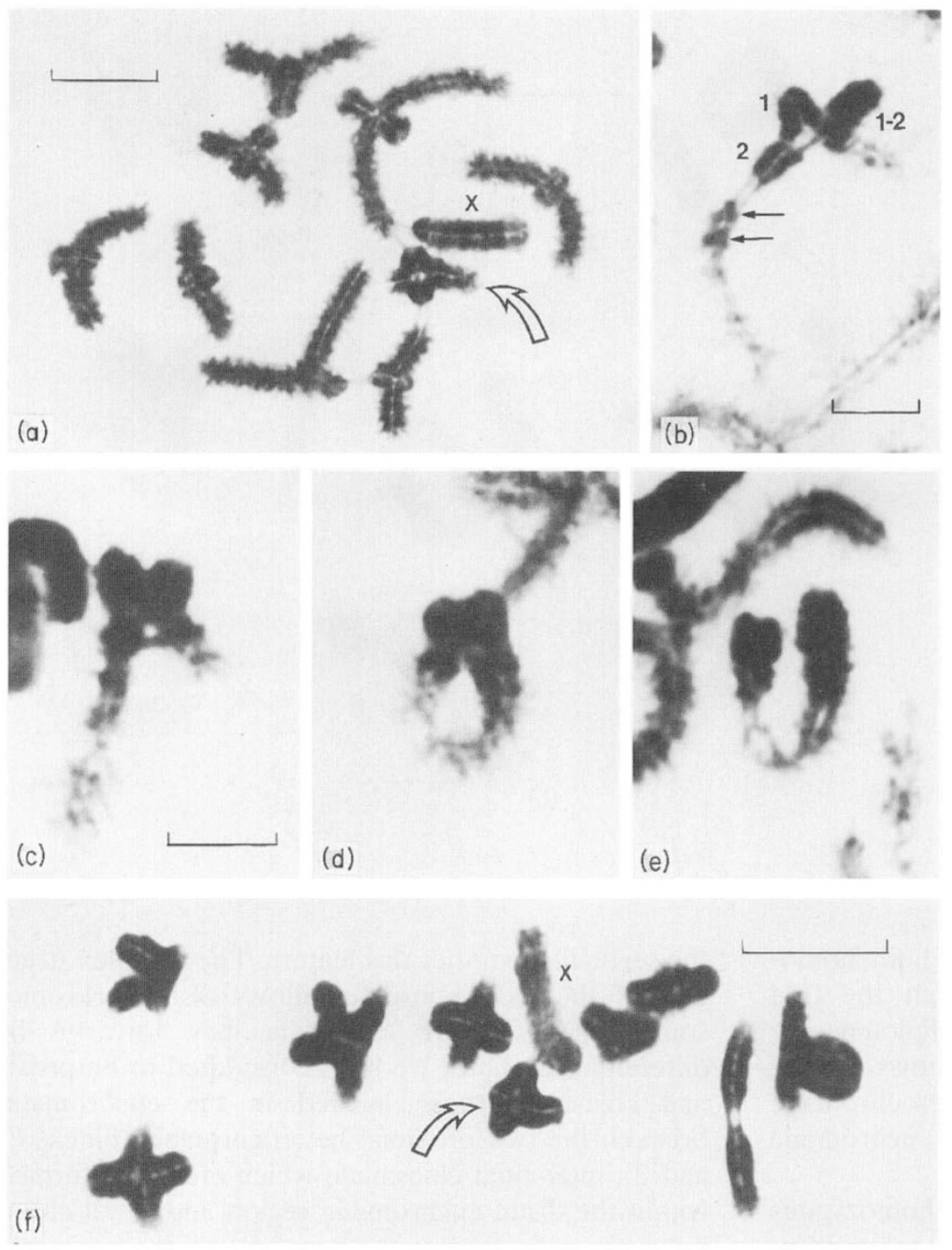

Fig. 3 Megameric bivalents heterozygous for the distal euchromatic segment $(S / E)$. Orcein staining.

(a) Diakinesis. The megameric bivalent (arrow) is clearly heterozygous for the presence of a distal euchromatic segment. X: sex chromosome. Bar represents $10 \mu \mathrm{m}$. (b) Selected S/E early diplotene bivalent with a proximal chiasma. The standard chromosome shows two joined proximal heterochromatic blocks (1-2) and a short distal euchromatic region. Its homologue also presents the two heterochromatic blocks $(1,2)$ and two thin heterochromatic bands (arrows) interspersed within the large distal euchromatic segment. Bar represents $5 \mu \mathrm{m}$.

(c)-(e) Selected diplotene S/E bivalents with proximal (c) and distal (e) chiasmata and proximal and distal associations (d). Bar represents $5 \mu \mathrm{m}$. (f) Metaphase I. The S/E megameric bivalent (arrow) presents a proximal chiasma. Bar represents $10 \mu \mathrm{m}$.

Table 2 Frequencies of the heterochromatic $(\mathrm{H})$ and euchromatic (E) segments during 3 consecutive years of sampling

\begin{tabular}{lccc}
\hline Segment & $\begin{array}{c}1986 \\
(n=100)\end{array}$ & $\begin{array}{c}1987 \\
(n=120)\end{array}$ & $\begin{array}{c}1988 \\
(n=45)\end{array}$ \\
\hline $\mathrm{H}$ & 0.035 & 0.033 & 0.022 \\
$\mathrm{E}$ & 0.060 & 0.037 & 0.044 \\
\hline
\end{tabular}

scored (Table 4). There are significant differences in the frequencies between diplotene and diakinesis $\left(\chi_{2}^{2}=26.52, P<0.005\right)$ and diplotene and metaphase I $\left(\chi \frac{2}{2}=7.05, P<0.01\right)$. By contrast, the distribution is not different between diakinesis and metaphase I bivalents $\left(\chi_{2}^{2}=1.23, \quad P>0.5\right)$. The percentage of bivalents with two presumed chiasmata decreases dramatically in diakinesis and metaphase I cells (Table 4). Interest-
Table 3 Number and percentage of univalents $(\mathrm{U})$ and chiasmata located in proximal $(\mathrm{P})$, interstitial (I) and distal (D) regions in the five different kinds of megameric bivalents analysed. Notice the absence of proximal chiasmata in $\mathrm{H} / \mathrm{H}$ bivalents and of interstitial chiasmata in S/E and S/EH bivalents

\begin{tabular}{lccccccccc}
\hline Bivalent & P & $\%$ & I & $\%$ & D & $\%$ & Total & U & $\%$ \\
\hline S/S & 33 & $(13.5)$ & 49 & $(20.1)$ & 162 & $(66.4)$ & 244 & - & - \\
S/H & 10 & $(8.5)$ & 13 & $(11.0)$ & 95 & $(80.5)$ & 118 & - & - \\
H/H & - & - & 15 & $(14.4)$ & 89 & $(85.6)$ & 104 & - & - \\
S/E & 297 & $(91.4)$ & - & - & 28 & $(8.6)$ & 325 & 5 & $(1.5)$ \\
S/EH & $75(82.4)$ & - & - & $16(17.6)$ & 91 & 11 & $(10.8)$ \\
\hline
\end{tabular}

ingly, this decrease is of similar magnitude to the increase in the frequency of bivalents with proximal chiasmata (Table 4). This suggests that only some distal associations present in diplotene bivalents with two 
Table 4 Number and percentage of megameric bivalents heterozygous for the distal euchromatic supernumerary segment $(\mathrm{S} / \mathrm{E})$ with proximal $(\mathrm{P})$, proximal/distal (P/D) and distal (D) associations during three different first meiotic division stages

\begin{tabular}{lrcrrrrr}
\hline Meiotic stage & P & $\%$ & P/D & $\%$ & D & $\%$ & Total \\
\hline Diplotene & 114 & $(79.7)$ & 20 & $(14.0)$ & 9 & $(6.3)$ & 143 \\
Diakinesis & 224 & $(91.1)$ & 3 & $(1.2)$ & 19 & $(7.7)$ & 246 \\
Metaphase I & 68 & $(91.9)$ & 2 & $(2.7)$ & 4 & $(5.4)$ & 74 \\
\hline
\end{tabular}

associations are true chiasmata (Fig. $4 \mathrm{a}, \mathrm{c}$ ). On the other hand, the frequency of bivalents with a single distal association is similar in these three stages (Table 4, Fig. 4d), indicating that a true chiasma forms in bivalents with only one distal association. Taking into account these results, and to compare the chiasma distribution in standard $(\mathrm{S} / \mathrm{S})$ and heterozygous $(\mathrm{S} / \mathrm{E})$ bivalents, the diplotene data have been excluded and those from diakinesis and metaphase I have been combined. The ten chiasmata present in the five bichiasmate bivalents found during diakinesis and metaphase
Fig. 4 Distal euchromatic segment (E). Orcein staining. (a) Diakinesis. The S/E megameric bivalent (arrow) shows two chiasmata, proximally and distally located. (b) Diakinesis. The megameric chromosomes (arrow) appear as univalents. (c) Metaphase I. Ring configuration of the $\mathrm{S} / \mathrm{E}$ megameric bivalent (arrow) showing two chiasmata (compare with a). (d) Metaphase I. The S/E megameric bivalent (arrow) shows a single distal chiasma. In all figures bar represents $10 \mu \mathrm{m}$.

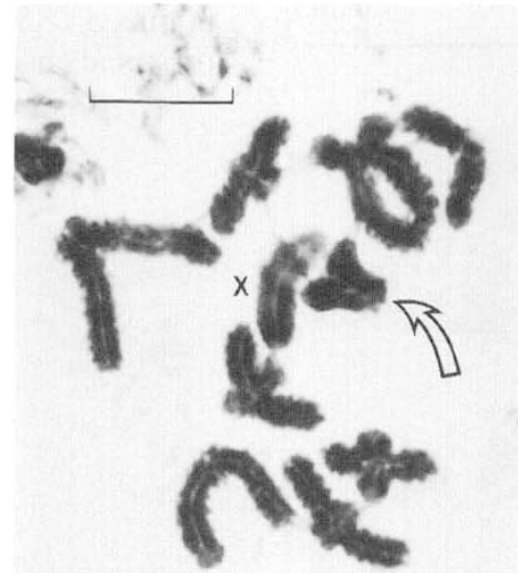

(a)

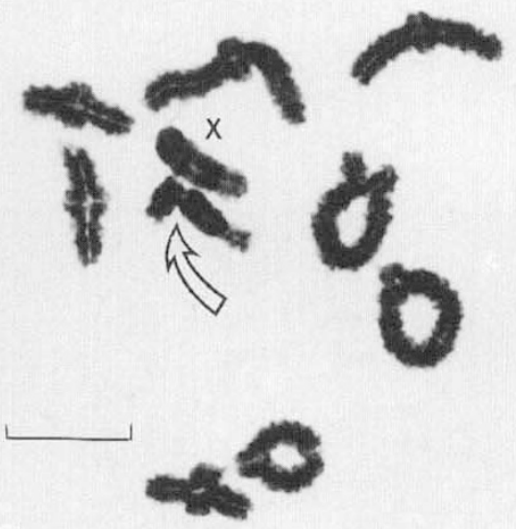

(b)

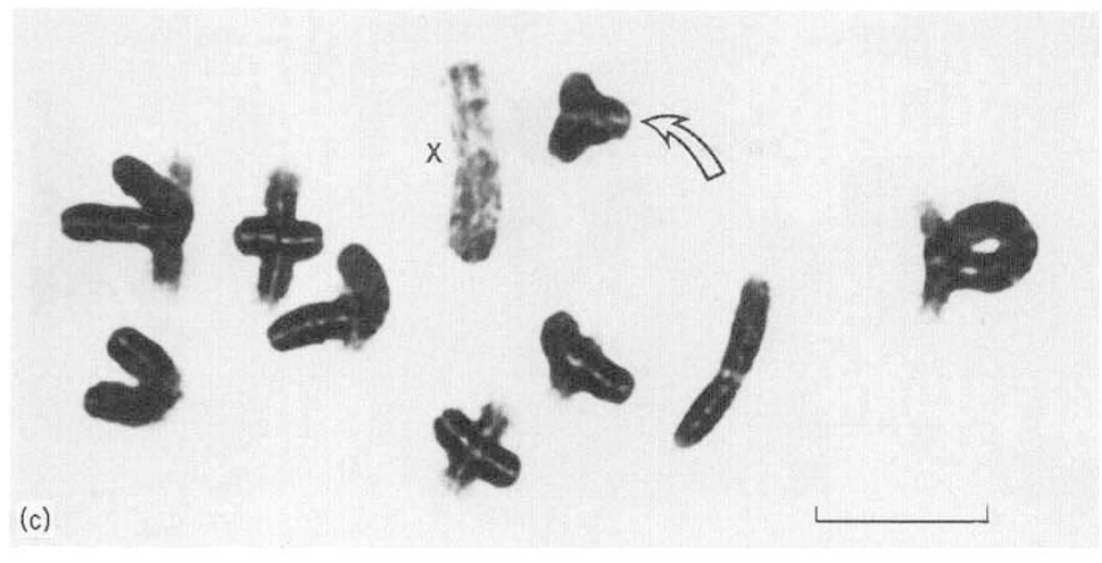

(d)

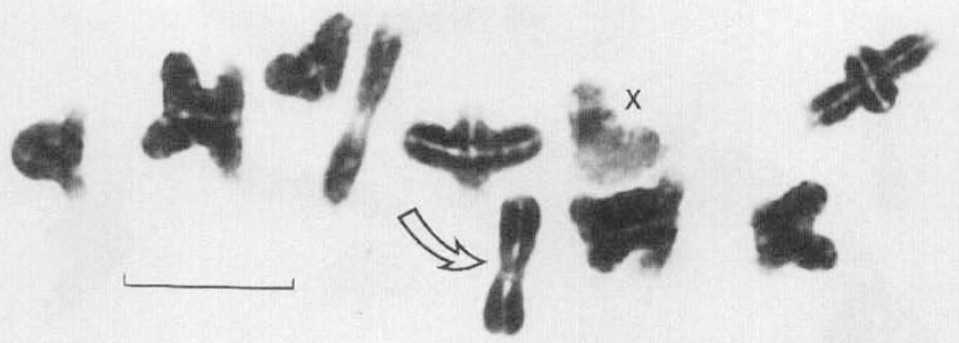


Table 5 Series of contingency $\chi^{2}$ tests comparing chiasma distribution patterns between the five types of megameric bivalents

\begin{tabular}{lrc}
\hline $\begin{array}{l}\text { Kinds of megameric } \\
\text { bivalents compared }\end{array}$ & \multicolumn{1}{c}{$\chi_{2}^{2}$} & $P$ \\
\hline SS/SE & 350.27 & $<0.005$ \\
SS/SH & 7.76 & $<0.025$ \\
SS/HH & 19.06 & $<0.005$ \\
SS/SEH & 145.57 & $<0.005$ \\
SE/SH & 282.83 & $<0.005$ \\
SE/HH & 313.03 & $<0.005$ \\
SE/SEH & 5.13 & $<0.025$ \\
SH/HH & 9.49 & $<0.010$ \\
SH/SEH & 117.40 & $<0.005$ \\
HH/SEH & 140.51 & $<0.005$ \\
\hline
\end{tabular}

I have been assigned to both proximal and distal chiasma categories (Table 3). A contingency test reveals that the chiasma distribution between standard $(\mathrm{S} / \mathrm{S})$ and heterozygous bivalents $(\mathrm{S} / \mathrm{E})$ is significantly different (Table 5). This is due to the displacement of the chiasma from distal to proximal locations in heterozygous bivalents (Table 3, Fig. 7). On the other hand, in some cases ( 1.5 per cent) megameric univalents were scored in prophase I and metaphase I cells (Fig. 4b, Table 3).

Heterozygous bivalents which possess a proximal heterochromatic segment $(\mathrm{S} / \mathrm{H})$ always form a single chiasma (Fig. 5c-e), preferentially at the distal end (80.5 per cent) (Table 3 ). In homozygous bivalents $(\mathrm{H} /$ $\mathrm{H})$ the frequency of distal chiasmata is equally pronounced (85.6 per cent) (Fig. 5f) but, interestingly, proximal chiasmata are never found (Table 3, Fig. 7). In
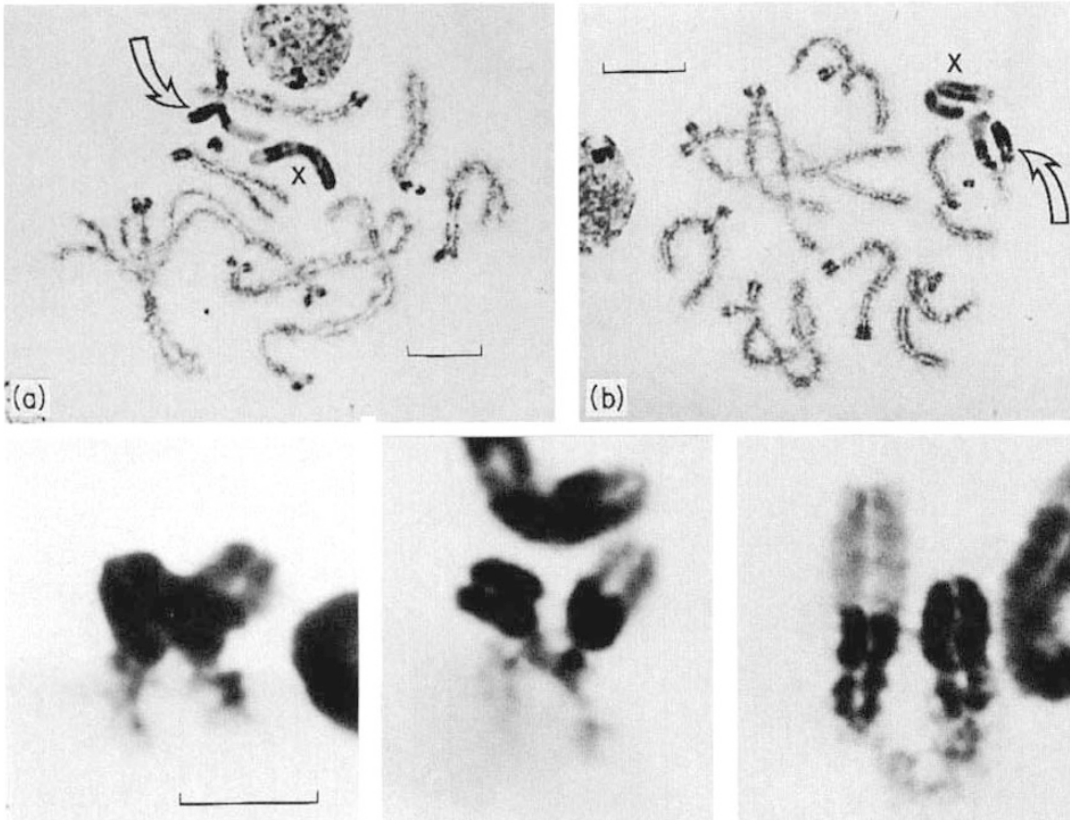

(c)

\begin{abstract}
(d)
\end{abstract}

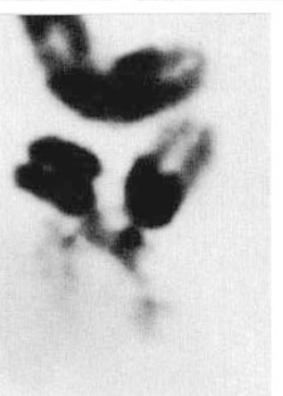

(e)
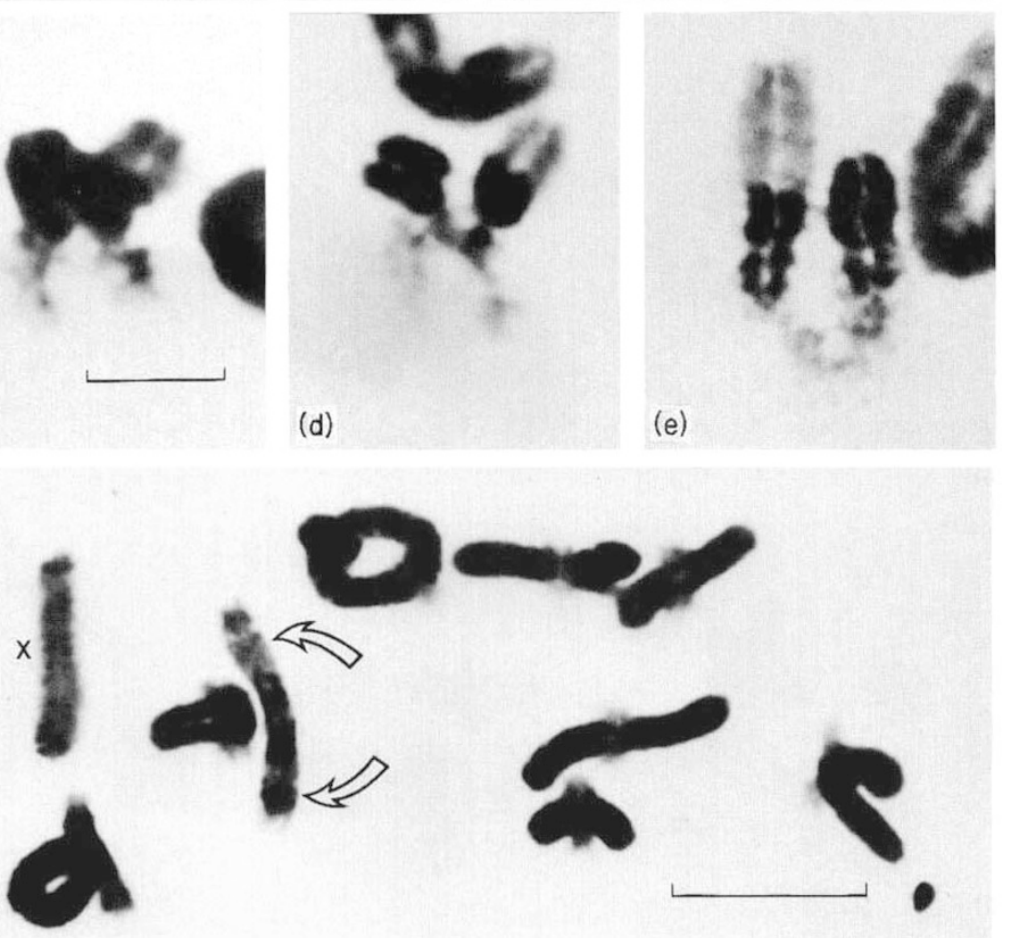

(f)

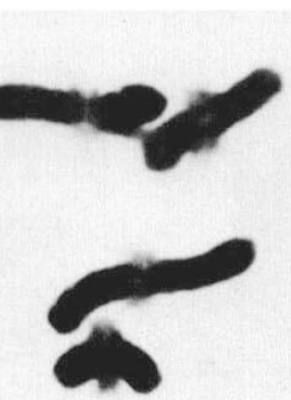

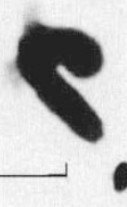

Fig. 5 Proximal heterochromatic segment $(\mathbf{H})$. Orcein staining. (a) and (b) The megameric bivalent (arrow) is heterozygous for the presence of the proximal heterochromatic segment $(\mathbf{H})$ which is negatively heteropycnotic during early diplotene (a) and diplotene (b). Bar represents $10 \mu \mathrm{m}$. (c)-(e) Selected diplotene $\mathrm{S} / \mathrm{H}$ megameric bivalents with proximal (c), interstitial (d) and distal (e) chiasmata. Bar represents $5 \mu \mathrm{m}$. (f) Metaphase I. Megameric bivalent homozygous for the presence of the proximal heterochromatic segment $(\mathbf{H})$ (arrows). Bar represents 10 $\mu \mathrm{m}$. 
both cases, the chiasma distribution is significantly different from that observed in standard bivalents $(\mathrm{S} / \mathrm{S})$ (Table 5). It must be stressed that no univalents were found either in heterozygous $(\mathrm{S} / \mathrm{H})$ or homozygous $(\mathrm{H} /$ $\mathrm{H})$ individuals.

Two individuals possessing a megameric bivalent doubly heterozygous for the presence of the distal euchromatic and the proximal heterochromatic segments both located in one of the homologues have also been analysed $(\mathrm{S} / \mathrm{EH})$ (Figs $1 \mathrm{~d}$ and $6 \mathrm{a}, \mathrm{b})$. Some bivalents in diplotene cells show two associations (Fig. $6 \mathrm{~d}$ ), as do bivalents heterozygous for the distal euchromatic segment $(S / E)$. However, they commonly form a single proximal (Fig. 6c) or distal chiasma (Fig. 6e). No interstitial chiasmata were observed. During diakinesis and metaphase I, 10.8 per cent of cells presented megameric univalents. No bivalents with two associations were detected (Table 3). Consequently, only bivalents from those stages have been scored to compare with the chiasma distribution of standard bivalents $(\mathrm{S} / \mathrm{S})$. A contingency analysis reveals that the chiasma distribution found in doubly heterozygous bivalents $(\mathrm{S} / \mathrm{EH})$ is different from that of standard bivalents $(\mathrm{S} / \mathrm{S})$ (Table 5). This is due to the displacement of the single chiasma to proximal regions in doubly heterozygous bivalents (Table 3, Fig. 7). However, this displacement is not as strong as in bivalents heterozygous for the euchromatic segment (S/E) (Table 3, Fig. 7). In fact, both kinds of heterozygous bivalents ( $\mathrm{S} / \mathrm{E}$ and $\mathrm{S} / \mathrm{EH}$ ) show significant differences in their respective chiasma distributions (Table 5). Finally, the overall chiasma distributions observed in the five kinds of megameric bivalents observed are significantly different (Table 5).

\section{Discussion}

The two kinds of supernumerary segments $(\mathrm{E}$ and $\mathrm{H})$ affecting the megameric chromosome of $P$. conica are present in very low frequencies in the sampled population (Table 2). These frequencies are maintained during the 3 years of sampling and explain why we have found only five out of ten possible karyomorphs (Table 1). This limits our analysis of the influence of the supernumerary segments on chiasma distribution and chromosome behaviour of the megameric pair. It must be stressed that, as far as we know, this is the first report in which two segments of different nature, one euchromatic and the other heterochromatic, and different locations have been found on the same chromosome. This has offered us a unique opportunity to analyse and compare the individual and combined effects that these segments exert on the chiasma distribution of the same bivalent, i.e. the megameric pair.

Standard megameric bivalents $(\mathrm{S} / \mathrm{S})$, which have two proximal heterochromatic blocks, always show a single chiasma that is usually distally located. However, chias-
Fig. 6 Doubly heterozygous megameric bivalents $(\mathrm{S} / \mathrm{EH})$. Orcein staining. (a) Late diplotene. The S/EH megameric bivalent (arrow) shows proximal and distal associations. Bar represents $10 \mu \mathrm{m}$. (b) Diakinesis. The $\mathrm{S} / \mathrm{EH}$ megameric bivalent (arrow) has a distal chiasma. Bar represents $10 \mu \mathrm{m}$. (c)-(e) Selected S/EH diplotene bivalents with proximal (c) and distal (e) chiasmata and proximal and distal associations (d). Bar represents $5 \mu \mathrm{m}$.
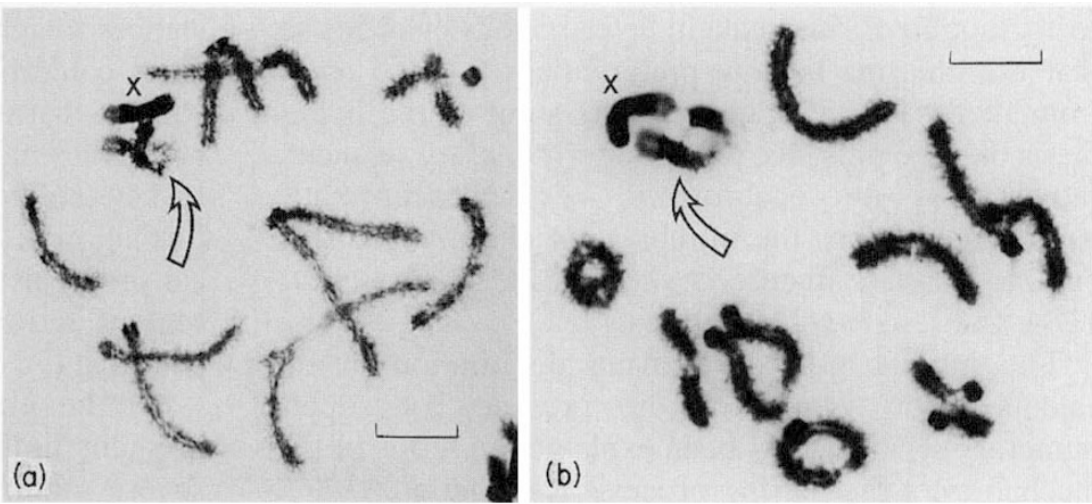

(a)

(b)

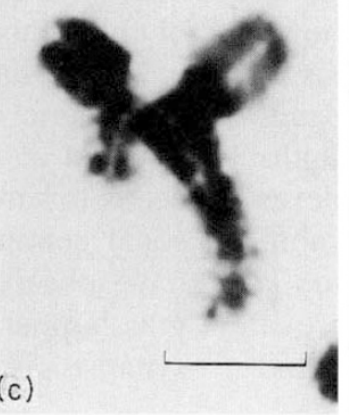

(d)

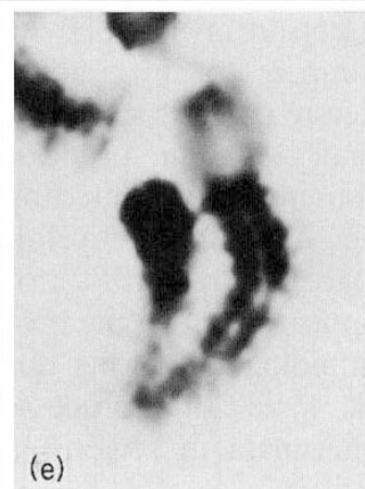




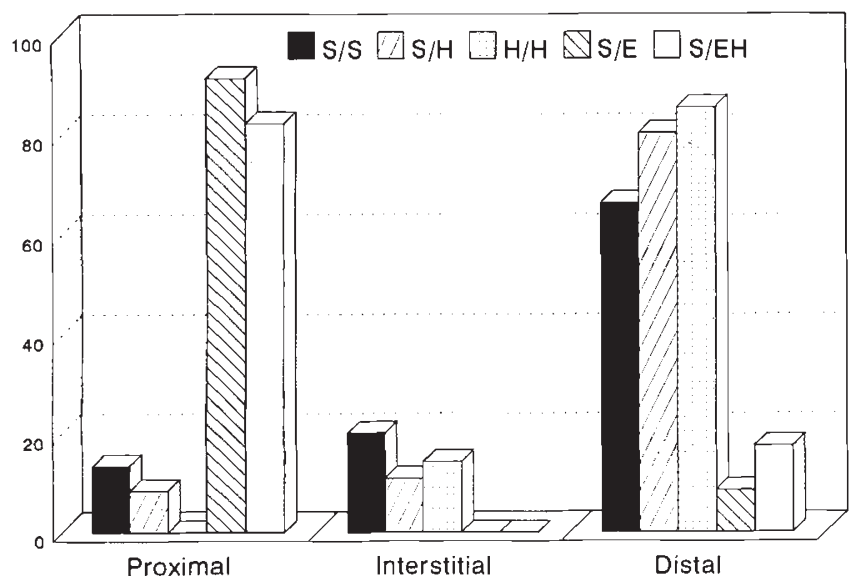

Fig. 7 Chiasma distribution in the five types of megameric bivalents analysed.

mata are also formed at proximal locations (13.5 per cent). The analysis of pairing progression in surfacespread zygotene nuclei of $P$. conica indicates that the megameric chromosomes initiate pairing at their noncentromeric distal ends and that complete pairing is achieved early on (J. L. Santos, personal communication). These data may explain why distal chiasmata are preferentially formed and imply that heterochromatic blocks interfere but do not abolish the recombination in the euchromatic region between them, leading to the formation of proximal chiasmata. By contrast, the addition of both segments $(\mathrm{H}$ and $\mathrm{E})$ produces a dramatic redistribution of chiasmata in heterozygous bivalents so that the chiasma is now preferentially formed away from them (Fig. 7). These results support the hypothesis that the presence of the supernumerary segment, rather than the euchromatic or heterochromatic nature, determines the intrabivalent chiasma redistribution (García-Lafuente et al., 1983; Camacho et al., 1984; Cabrero et al., 1986).

The modification of chiasma distribution in bivalents heterozygous for the presence of supernumerary segments has been explained in terms of the mechanics of the pairing process (Rufas et al., 1986). Electron microscope studies of surface-spread grasshopper pachytene nuclei containing bivalents heterozygous for the presence of segments have shown that two main processes may occur: (i) synapsis is sometimes prevented by misalignment of homologues near the nuclear envelope due to their different lengths (Moens et al., 1989), or (ii) synaptonemal complexes appear all along the bivalents causing a degree of nonhomologous pairing due to heterosynapsis (Santos et al., 1993). Both processes might explain the absence of chiasmata in regions adjacent to the segments and consequently the chiasma redistribution observed in heterozygous bivalents.

We have observed that bivalents homozygous for the presence of the proximal heterochromatic segment $(\mathrm{H} /$ $\mathrm{H})$ have a chiasma distribution significantly different from that in standard bivalents $(\mathrm{S} / \mathrm{S})$. Moreover, in these homozygous bivalents the chiasma pattern is more severely readjusted than in heterozygous bivalents $(\mathrm{S} / \mathrm{H})$ and proximal chiasmata are not formed (Fig. 7). The abolition of chiasmata near the segments has also been reported in bivalents homozygous for the presence of a distal segment in the grasshopper Chorthippus parallelus (Navas-Castillo et al., 1985). The chiasma redistribution observed in structural homozygous bivalents has been the subject of some debate. John (1981) and Navas-Castillo et al. (1985) found that the chiasma distribution in structural homozygotes was significantly different from that found in basic homozygotes. Navas-Castillo et al. (1985) suggested that the presence and not the structural heterozygosity was responsible for the chiasma redistribution. However, de la Torre et al. (1986) observed that the chiasma distribution in structural homozygotes of two grasshopper species of the genus Arcyptera was similar to that of basic homozygotes and proposed that the heterozygosity of the bivalent accounted for the chiasma redistribution rather than the presence of the segment. In structural homozygotes the homologues are of equal length and a correct pairing, with the concomitant formation of a synaptonemal complex along the entire length of the bivalent, is expected. Under such circumstances the chiasma distribution in structural homozygotes could be similar to that found in basic ones. We suggest that the addition of segment $\mathrm{H}$ to both megameric chromosomes, that normally possess two proximal heterochromatic blocks which interfere with the formation of proximal chiasmata, may cause topological problems by inhibiting pairing in the neighbouring regions and then promoting the abolition of proximal chiasmata.

On the other hand, the presence of the euchromatic segment both in S/E and S/EH bivalents promotes severe modifications of the pairing behaviour of the megameric chromosomes: the consequent absence of interstitial chiasmata, and significantly high frequencies of univalents.

As we have previously noted, pairing of standard megameric chromosomes of $P$. conica seems to be initiated at the non-centromeric distal end and proceeds towards the centromeric end (J. L. Santos, personal communication). Recently Santos et al. (1993) have observed that in the smallest bivalents of the grasshopper Chorthippus jacobsi the normal pattern of synapsis is modified when distal heterochromatic 
segments are present in heterozygotes. While pairing usually starts at or near the telomeric end in standard bivalents, pairing begins at the centromeric end in heterozygous bivalents. We think that a similar situation may occur in megameric bivalents heterozygous for the distal euchromatic segment (S/E and S/EH). In this case, pairing may start at the centromeric end and proceed towards the telomeric end. This would favour the formation of proximal chiasmata. The absence of interstitial chiasmata may be explained by either heterosynapsis or asynapsis between the interstitial regions of both the standard and the segmented megameric chromosomes (E or $\mathrm{EH}$ ) due to their lack of homology (see Fig. 1). However, we think that the appearance of a very low frequency of $S / E$ bivalents with two true chiasmata during diakinesis and metaphase I favours the hypothesis of asynapsis between interstitial regions. The discontinuity in pairing caused by the formation of a loop in an interstitial position may relax or eliminate the interference, thereby allowing the formation of a second chiasma.

In any case, the true distal chiasmata scored in diakinesis and metaphase I S/E and S/EH bivalents indicate the existence of homology and the occurrence of pairing between the end of the standard chromosome and the end of the supernumerary euchromatic segment. This suggests that at least the end of the actual euchromatic segment could have arisen by duplication of the distal euchromatic region of the standard chromosome.

Unless two chiasmata form in S/E bivalents, asynapsis may occur in some cells of $\mathrm{S} / \mathrm{E}$ and $\mathrm{S} / \mathrm{EH}$ karyomorphs as a significant frequency of univalents is detected in both cases (Table 3). In particular, in the S/EH karyomorph 10.8 per cent of the cells contained univalents. As we have previously noted, the presence of segment $E$ in this karyomorph could promote the initiation of pairing at their centromeric ends. However, as in the case of $\mathrm{S} / \mathrm{H}$ and $\mathrm{H} / \mathrm{H}$ bivalents, the addition of segment $\mathrm{H}$ in the $\mathrm{S} / \mathrm{EH}$ karyomorph may interfere with the formation of proximal chiasmata. This interference is obvious in $\mathrm{S} / \mathrm{EH}$ bivalents because the frequency of proximal chiasmata is lower than that observed in S/E bivalents (Fig. 7). The extreme interference inhibits pairing and promotes the appearance of univalents. In our opinion, the chiasma redistribution that occurs in bivalents with supernumerary segments depends primarily upon the degree of pairing between homologues. The pairing may be affected by several factors: (i) the euchromatic or heterochromatic nature of the segment which, due to different condensation processes, may influence their length during zygotene and pachytene; (ii) the location of the segment (proximal, interstitial or distal); (iii) the size of the carrier chromosome, which determines the places where pairing progression initiates; (iv) the possible homology between the segment and the standard chromosome; and $(\mathrm{v})$ the structure of the standard chromosome.

\section{Acknowledgements}

We express our sincere thanks to Dr P. L. Mason for reviewing the manuscript. This paper was supported by grants PB 90/0192, PB 91/0009 and CE 91/0010 awarded by the Comisión Interministerial de Ciencia y Tecnología and Dirección General de Investigación Científica y Técnica (Spain).

\section{References}

CABRERo, J., NAVAS-CASTIllo, J. AND CAMACHO, J. P. M. 1986. Effects of supernumerary chromosome segments on the activity of nucleolar organiser regions in the grasshopper Chorthippus binotatus. Chromosoma, 93, 375-380.

CAMACHO, J. P. M., VISERAS, E., NAVAS, J. AND CABRERo, J. 1984. C-Heterochromatin content of supernumerary chromosome segments of grasshoppers: detection of a euchromatic extra segment. Heredity, 53, 167-175.

GARCIA-LAFUENTE, R., LOPEZ-FERNANDEZ, C. AND GOSALVEZ, J. 1983. Extra heterochromatin in natural populations of Gomphocerus sibiricus (Orthoptera: Acrididae). 2. Chiasma distribution in the $\mathrm{M}_{7}$ bivalent. Cytobios, 37, 149-155.

GoSALVEZ, J., BELLA, J. L., LOPEZ-FERNANDEZ, C. AND MEZZANOTTE, R. 1987. Correlation between constitutive heterochromatin and restriction enzyme resistant chromatin in Arcyptera tornosi (Orthoptera). Heredity, 59, 173-180.

HewitT, G. M. 1979. Animal Cytogenetics, vol. 3: Insecta 1. Grasshoppers and Crickets. Gebrüder Borntraeger, BerlinStuttgart.

JOHN, B. 1973. The cytogenetic systems of grasshoppers and locusts. II. The origin and evolution of supernumerary segments. Chromosoma, 44, 123-146.

JOHN, B. 1981. Heterochromatin variation in natural populations. In: Bennett, M. D., Bobrow, M. and Hewitt, G. M. (eds) Chromosomes Today, vol. 7, pp. 128-137. George Allen and Unwin, London.

JOHN, B. AND KING, M. 1985. The inter-relationship between heterochromatin distribution and chiasma distribution. Genetica, 66, 183-194.

JOHN, B., KING, M., SCHWEIZER, D, AND MENDELAK, M. 1985. Equilocality of heterochromatin distribution and heterochromatin heterogeneity in acridid grasshoppers. Chromosoma, 91, 185-200.

MikLOS, G. L. G. AND NANKIVELL, N. 1976. Telomeric satellite DNA functions in regulating recombination. Chromosoma, 56, 143-167.

MOENS, P. B., BERNELOT-MOENS, C. AND SPYROPOULOS, B. 1989. Chromosome core attachment to the meiotic nuclear envelope regulates synapsis in Chloealtis (Orthoptera). Genome, 32, 601-610. 
NAVAS-CASTILlo, J., CABRERo, J. AND CAMACHO, J. P. M. 1985. Chiasma redistribution in bivalents carrying supernumerary chromosome segments in grasshoppers. Heredity, $\mathbf{5 5}$, 245-248.

RODRIGUEZ IÑIGO, E., BELLA, J. L. AND GARCIA DE LA VEGA, C. 1993. Heterochromatin differentiation between two species of the genus Dociostaurus (Orthoptera: Acrididae). Heredity, 70, 458-465.

RUFAS, J. S., SUJA, J. A. AND GARCIA DE LA VEGA, c. 1986. Generation by a polymorphic supernumerary segment of recombination in a normally achiasmate proximal region in Acrotylus insubricus (Scopoli) (Orthoptera: Acrididae). Can. J. Genet. Cytol., 28, 433-438.

RUIZ REJON, C. AND RUIZ REJON, M. 1985. Chromosomal polymorphism for a heterochromatic supernumerary segment in a natural population of Tulipa australis Link (Liliaceae). Can. J. Genet. Cytol., 27, 633-638.

SANTOS, J. L., DEL CERRo, A., FERNANDEZ, A. AND DIEZ, M. 1993. The relationship between synapsis and chiasma distribution in grasshopper bivalents heterozygous for supernumerary segments. Heredity, 70, 135-141.

SENTIS, C., SANTOS, J. AND FERNANDEZ-PIQUERAS, J. 1989. Breaking up the chromosomes of Baetica ustulata by in situ treatments with restriction endonucleases. Genome, 32, 208-215.

TORRE, J, DE LA, LOPEZ-FERNANDEZ, C., NICHOLS, R. AND GOSALVEZ, J. 1986. Heterochromatin readjusting chiasma distribution in two species of the genus Arcyptera: the effects among individuals and populations. Heredity, 56, 177-184. 